\title{
Integrated Maintenance and Cost Optimisation of Libyan Cement Factory using Witness Simulation
}

\author{
Elbahlul. M. Abogrean \& Muhammad Latif \\ School of Engineering, Manchester Metropolitan University \\ Chester St, Manchester M1 5GD, UK \\ Tel: 44-(0)-161-247-6264_E-mail: aabogrean2007@yahoo.com \& M.Latif@mmu.ac.uk
}

Received: February 23, 2012 Accepted: March 9, 2012 Published: April 1, 2012

doi:10.5296/jmr.v4i2.1437～URL: http://dx.doi.org/10.5296/jmr.v4i2.1437

\begin{abstract}
This paper looks into how simulation can be used and developed to combat and aid integrated maintenance and cost optimisation of Libyan cement factory by using simulation as an intelligent maintenance tool to enable intelligent decisions to be made by maintenance management. The cost of preventive maintenance against corrective maintenance, the loss of production and the delay in schedule. Also this paper presents a methodology by integrating maintenance, repair and replacement decisions in bridge management based on reliability, optimization, and life-cycle cost. The overall total cost incurred per minute due to machine failure for more intelligent maintenance decision making. The end result of the model identifies a true to life cost of preventive and corrective maintenance incurred by organisation due to failures.
\end{abstract}

Keywords: Simulation, Intelligent maintenance, Cement, Witness, Lean manufacturing, Decision making 


\section{Introduction}

Industrial organisations recognise that having an effective maintenance management program is fundamental to the success of all manufacturing operations and keeping costs down to achieve world class lean manufacturing.[1] Hence it is of interest to all industrial organisations to predict and prevent failures rather than fail and fix.

This paper looks into maintenance of a single machine based on many assumptions simulated by a Witness model; there are two types of maintenance i.e. preventive and corrective. The costs incurred to the organisation and times needed are implemented via the use of mathematical equations. This enables the user to view clearly the different costs, whether for a single maintenance activity or for all the maintenance requirements that have been undertaken within a 30 day period. [2, 3]

This model will demonstrate and highlight the true integration of maintenance within a single machine over a period of 30 days and further stress the importance of time and costs incurred to the organisation and the difficulties faced therein, hence the much needed intelligent maintenance implementations.

\section{Maintenance}

The significance of an effective maintenance management program should not be ignored as its role is very important in the effectiveness of lean manufacturing. It is required to effectively reduce waste and run an efficient, continuous manufacturing operation, business, or service operation. The cost of regular maintenance i.e. preventive is very small when it is compared to the cost of a major breakdown i.e. corrective, at which time there is no production. [4]

The reason of regular maintenance is to make sure that all equipment required for production is operating at the highest rate of efficiency at all times if not $100 \%$. Through short intelligent daily inspections, cleaning, lubricating, and making minor adjustments, minor problems can be detected and corrected before they become a major problem that can shut down a production line via the means of breakdown where corrective action is required and production is lost. [5]

A good maintenance program requires the participation and support by everyone from the very top to the very bottom. The daily intelligent inspection enables intelligent decisions to be made as important information is gathered regarding different aspects of machinery i.e. the general ware and tear of certain parts, problem/ disruption areas due to unknown reasons etc. The main idea behind this is to keep ahead of maintenance, by knowing where all the problem areas are, the easiest way to combat such issues and most importantly, to carry out preventive work on a regular basis based on intelligent information to ensure breakdowns do not occur or at least keep them to a bare minimum. "Changing from a FAIL and FIX approach to a PREDICT and PREVENT approach"

A machines breakdown true cost is very difficult to measure as the cost for a machine breakdown is more than just the maintenance labour and materials to make the repair. Actual costs equate too much more as many aspects have to be considered especially in the industrial organisations and global economies, as organisations have very precise deadlines to meet. Where production has stopped due to breakdown of machinery or due to the availability of spare parts hence targets are not being met in terms of production output results in deadlines not being met and further fines being incurred[6,7]. 
Maintenance for a very long time has been looked at as a dirty and boring job with no real significance.[8] A job that did not add value to the productivity of the organisation and that was very narrow in terms of responsibility as management previous thought or did nothing about, other than wait for the technical staff to sort out the problem so they could proceed with the production.

This has changed dramatically in the past two decades as industrial organisations strive very hard via the means investment into research and development and understand it is very important to get the best productivity from any and all equipment as this adds essential value to the bottom line.

The simple question, "Why do we need to maintain things regularly?" The answer is, "To keep things as reliable as possible." However, the real question is, "How much change or wear has occurred since the last round of maintenance?" Generally the answer is, "I do not know." This is the main reason behind intelligent maintenance, where it enables the gathering of information to make more effective informed decisions to enable efficient processing to follow.

Autonomous maintenance is very important as it develops operators to be able to take care of small maintenance jobs on the equipment they use on a daily basis and to a certain extent to using the equipment for such a long period of time, they may also understand certain protocols that will enable them to make effective decisions, further they as operators will take note of data regarding the machineries and be fully informed rather than a technical staff that may just simply look at the technicalities, so both operators and technical staff as stated before, regardless of hierarchy need to work together to achieve the very best. This also falls hand in hand with philosophies such as Just-In-Time where the normal operators should receive increased responsibility, training and education so they can take care of the equipment that they use and the skilled maintenance people can concentrate on technical repairs. This further helps to develop intelligent information as they spend the most amount of time with the designated machines/equipment.

With the era of technology at hand with advanced computing and information technologies, more equipment and machines are equipped with sensors on critical parts of machines to warn of potential failures before they fail so they can be corrected before they stop production. Integrated computerised systems are the core of intelligent maintenance as well as e-maintenance, where computerised systems aid development of management in order to make a more informed decision with regards to undertaking or being prepared to carry out maintenance of all sorts.

Intelligent maintenance systems (IMS) Predict and Forecast equipment performance so "Zero-Breakdown" status can be made possible and not a possibility of the past. Zero downtime focuses on machine performance strategies to minimize failures. Data comes from sensors on equipment and machines and the information gathered by the organisation i.e. quality data, past history, failures, repairs and trending etc. Only looking at data from these sources (current and historical), it can predict future performance.

Industrial organisations today depend on sensor-driven management systems that provide alerts, alarms and indicators. Most factory downtime is caused by these unexpected situations. There is no alert provided that looks at normal wear and tear over time. If it were possible to monitor the normal wear, then it would be possible to forecast upcoming situations and perform maintenance tasks before breakdown occurs hence the need of intelligent preventive maintenance. [8] 
Intelligent maintenance is to monitor equipment performance. If wear and tear starts to occur, there is enough time to carry out preventive maintenance on that particular the area before failure. A machine can self-assess its health and trigger its own service request as needed and developed in this model. If this model works, then we will have a product that can manage its own service performance, send out alerts regarding preventive and corrective maintenances before the actual failure. This will indicate ways to keep it running in a high-performance manner and most definitely result in lean manufacturing.

However, many industries due to economies of scale, global economies and increased competition from throughout the world simply and only focus on the bottom line, the cost of downtime has a big impact on profitability. For example, if equipment starts to wear, machines may be producing parts with unacceptable quality and not know it for a long time. Eventually, machine wear will seriously affect not only productivity but also product quality.

World Class organisations already have taken a game-changing approach, implementing a new service business model to change maintenance systems into smart service and asset management solutions. They reduce downtime and provide the ability to look ahead at the quality of products before they ship by closely watching equipment performance and machine wear. Rather than reactive maintenance of "Fail and Fix" organisations can indeed and are moving towards an intelligent "Predict and Prevent" maintenance.[9]

\section{Assumptions for costing and equations}

- Price of cement is based on 15 tonnes costing $£ 400$, which is $£ 27$ per tonne to the nearest pound.

- Operator’s salary is $£ 1200$ for 30 days of labour based on 12 hour shifts.

- Maintenance staff salary is $£ 2000$ for 30 days of labour based on 12 hours shifts.

- $\quad$ Preventive maintenance carried out costs the facility $£ 10$ for the use of stock.

- Corrective maintenance carried out costs the facility $£ 100$ per stock item.

\section{Assumptions for model processes}

- Maintenance personnel are fully qualified and experienced in undertaking any sort of maintenance required.

- Resources and spare parts are readily available to cater for any and all jobs.

- Machine is established to be as good as new after maintenance has been carried out.

- Model is based on a single machine.

- Bottlenecks do not exist in the supply to the machine neither the supply from the machine.

- Preventive maintenance is carried out approximately twice a day as the machines work continuously non-stop based on intelligent data.

- The estimated lifespan of the spare parts for corrective maintenance to be undertaken where parts need to replaced is 14 days based on intelligent data.

- $\quad$ Model will run continuously for 30 days 


\section{Macrothink}

\section{Changes applied to model}

- Preventive maintenance now takes a uniform time of 15 to 20 minutes

- Corrective maintenance now takes a uniform time of 240 to 300 minutes

- Operators have now been reduced to 3

- All the activities within the machine now are based on a negexp time i.e. 1.1 minute for the first activity INSERT, 1.2 minutes for PROCESS, 1.3 minutes for PROCESSING, 1.4 minutes for READY and negexp 1.5 for EXIT.

\section{Equations for Costing}

The equations below shows how the simulation model calculates different costs that are incurred, further these equations can be used to derive the costs incurred by any part of the machine or any other machine in that case. For example;

1. Cost of Preventive Maintenance

1. $\mathrm{CPM}=(\mathrm{OHR} \times$ (number of operators) $/ 60 \times \mathrm{PMT})+(\mathrm{MHR} \times$ (number of maintenance staff) / $60 \times$ PMT) + CPS

2. Cost of Corrective Maintenance

1. $\mathrm{CCM}=(\mathrm{MHR} \times 2 / 60 \times \mathrm{CMT})+(\mathrm{OHR} \times 3 / 60 \times \mathrm{CMT})+\mathrm{CCS}$

3. Production Loss

1. $\mathrm{PL}=\mathrm{TMT} / \mathrm{APT}$

4. Average Process Time

1. $\mathrm{APT}=\mathrm{AT} / \mathrm{FL}$

5. Total Maintenance Time

1. $\mathrm{TMT}=\mathrm{PMT}+\mathrm{CMT}$

6. Schedule Delay Hours

1. $\mathrm{SDH}=\mathrm{TMT} / 60$

7. Schedule Delay Days

1. $\mathrm{SDD}=\mathrm{TMT} / 24$

\section{Abbreviations}

$\mathrm{AT}=$ Actual Time

APT $=$ Average Process Time per Load of Material

$\mathrm{FL}=$ Finished Loads

PMT = Preventive Maintenance Time

$\mathrm{CMT}=$ Corrective Maintenance Time

$\mathrm{TMT}=$ Total Maintenance Time 
CPS $=$ Cost of Preventive Stock

CCS $=$ Cost of Corrective Stock

$\mathrm{CPM}=$ Cost of Preventive Maintenance

CCM = Cost of Corrective Maintenance

$\mathrm{PL}=$ Production Loss

RVPL $=$ Retail Value of Production Loss

OHR = Operators Hourly Rate

MHR = Maintenance Hourly Rate

$\mathrm{SDH}=$ Schedule Delay Hours

SDD = Schedule Delay Days

\section{Maintenance Model Brief Overview}

Figure 1 below is a screen shot of the machine alone where two counters based on mathematical equation have been implemented,[10] one to show the average process time and the other to show the number of finished loads.

Mathematical process: Average process time has been worked out by dividing the actual time the machines have been on by the number of finished loads.

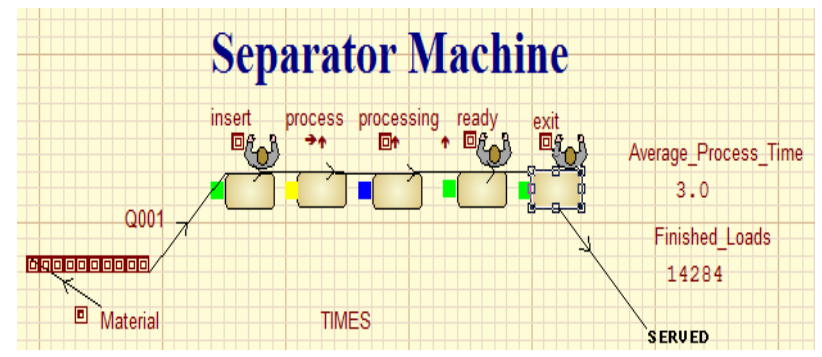

Figure 1. Separator Machine

Figure 2 below shows stock counters for preventive and corrective materials with a total counter at the very bottom. Further counters for cost have also now been applied based on the above mentioned assumptions i.e. a single preventive costs $£ 10$ and the costs of corrective is $£ 100$ per item therefore costing $£ 600$ for every corrective undertaken.

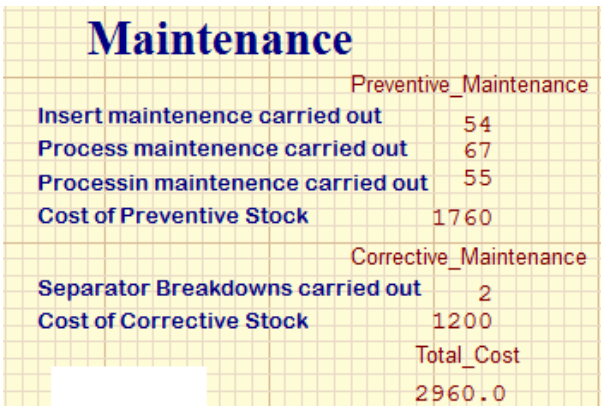

Figure 2. Maintenance 


\section{Macrothink Institute ${ }^{\mathrm{TM}}$}

Figure 3 below remains the same as it considers the availability of parts and restocks accordingly represented by simple counters that add and subtract accordingly.

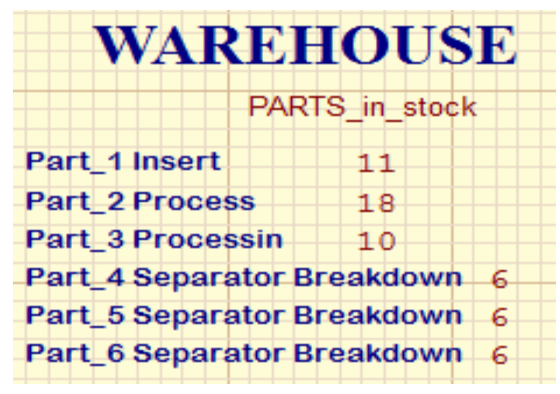

Figure 3. Warehouse

Figure 4 below represents the organisations employee salary; this had to be implemented to enable mathematical equations with regards to Castings for maintenance issues. It displays the operator and maintenance salary and the hourly rate that represents the salary. This is based on the assumptions hence hourly rate equals the salary divided by 30 days and thereafter divided by 12 hours for each shift.

\begin{tabular}{|c|c|c|}
\hline & Salary & Hourly_Rate \\
\hline Operators 123 & 1200.0 & 3.3 \\
\hline Maintenance & 2000.0 & 5.6 \\
\hline
\end{tabular}

Figure 4. Salary

Figure 5 below shows the delay in production due to time consumed by maintenance issues that have occurred and hence it has caused a delay in the actual production schedule. This equation is derived from the total maintenance time i.e. schedule delay equals total maintenance time divided by 60 minutes will give the number of hours spent and divided by 24 hours will represent the hours in days.

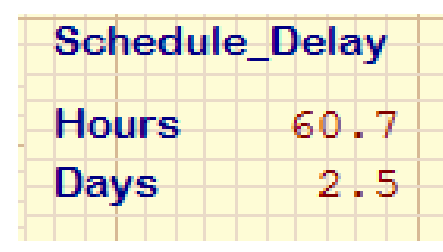

Figure 5. Schedule

Figure 6 below shows the production loss for preventive and corrective maintenance due to the time loss and the retail value of the loss due to maintenance. This takes into account the time spent on each maintenance and thereafter dividing it by the average process time that should represent the amount of production that could have produced within that time, the last counter i.e. RV_£ represents the retail value of the total production lost based on the assumptions of the price of cement. For example, 3 minutes of maintenance time equals 1 tonne of production that equals $£ 27$ 


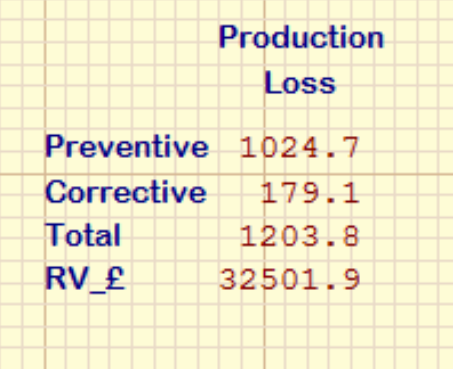

Figure 6. Production

Figure 7 below takes into account the amount of time preventive and corrective maintenances have consumed and the costs incurred thereby idle staff and the use of maintenance staff. The first set of counters indicate times i.e. the amount of time spent during maintenance and the second column represents loss in costs incurred in terms of salary i.e. operators hourly rate now has to be divided by 60 to get a minutely rate then has to be multiplied by the time spent on maintenance. This has to be done for all involving parties i.e. the number operators and maintenance staff.

\begin{tabular}{|c|r|r|}
\hline \multicolumn{2}{|c|}{ Maintenance_Times } & Loss_ $£$ \\
\hline Preventive & 3098.9 & 2850.3 \\
\hline Corrective & 541.5 & 1390.5 \\
\hline Total & 3640.4 & 4240.9 \\
\hline
\end{tabular}

Figure 7. Maintenance Times and Cost

Figure 8 represents the three main activities that are the core of the machine, where preventive and corrective maintenance is carried out, these are just simple equations to extract the time spent in each activity for maintenance needs that help to develop further very important equations as shown above.

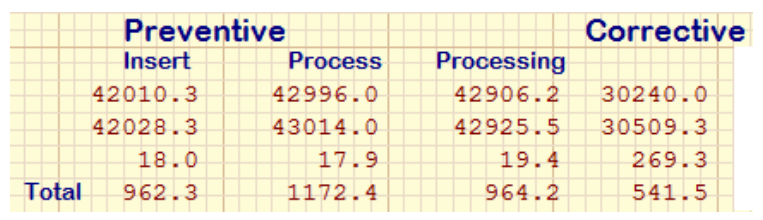

Figure 8. Preventive and Corrective Times

Figure 9 below is a full screen shot of the entire system that has been developed after a continuous 30 day period.

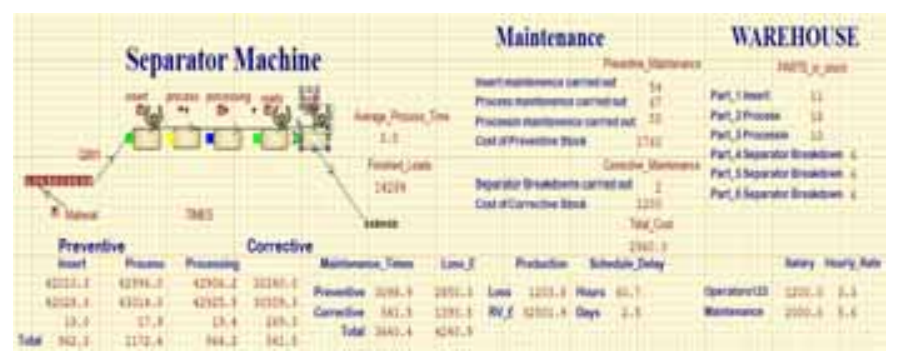

Figure 9. Entire System 


\section{Equations Implemented within the Model}

Figure 10 below shows how the mathematical equations have been replicated and programmed into the software according to the above stated equations and abbreviations. All the equations below have been implemented with the use of many Real Variables within the simulation program and thereafter the use of mathematical symbols to add, subtract and multiply where necessary according to the assumptions stated.

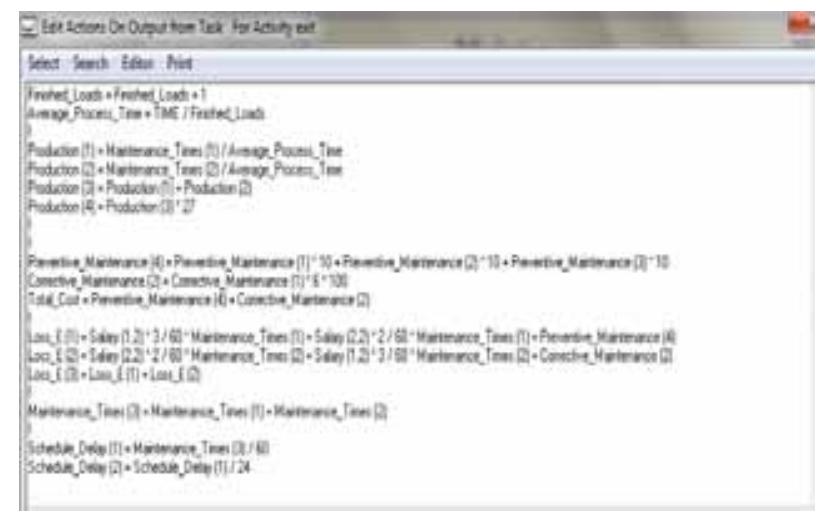

Figure 10.

\section{Findings}

After running the model for 30 days continuously, the statistics and counters show the cost of preventive and corrective maintenance, the production loss due to time consumed and the delay caused to the production schedule.

Cost of preventive maintenance for 30 days based on the labour hours spent equals $£ 2850$, the cost of stock to carry out the preventive work cost a further $£ 1760$, which equals a total of $£ 4610$. This does not take into consideration the production loss caused by the maintenance nor the schedule delay that has resulted because of maintenance alone. (Refer to figure 7 and 9)

Cost of corrective maintenance for 30 days based on the labour hours spent equals $£ 1390$, the cost of stock to carry out the preventive work cost a further $£ 1200$, which equals a total of $£ 2590$. This does not take into consideration the production loss caused by the maintenance nor the schedule delay that has resulted because of maintenance alone. (Refer to figure 7 and 9).

Combine the above preventive and corrective maintenance together and the total cost incurred in 30 days equals $£ 7200$, this is including the cost of stock to carry out the work.

Labour alone for maintenance for 30 days costs $£ 4240$, if we divide this cost by the number of minutes used for maintenance i.e. 4240 / 3640, we find that for every 1 minute spent undertaking maintenance, it is costing the organisation $£ 1.16$. (Refer to figure 7 and 9)

Productions loss due to maintenance is a very important aspect, as deadlines for target production need to be met, so they can move forward with the materials, finish off and dispatch to customers as soon as needed. The time consumed by maintenance can be seen as time production loss, as this time can be accounted for the production of materials, maintenance has consumed a total of 3640 minutes, this when translated into production equals to 1203 tonnes of production loss. This production holds an estimated retail value of $£ 32501$; this is a huge portion of the monthly production schedule, an estimated 1200 tonnes 
of extra materials has been lost. Further, due to the amount of time consumed by maintenance, 2.5 days out of 30 days is being spent on maintaining the single machine, this means, production is actually 2.5 days behind schedule. (Refer to figure 5 and 6)

\section{Conclusion}

From the above findings, we simply realised an estimated true cost incurred by the organisation for a single machine due to failures and further disruptions caused therein, as mentioned previously, this model not only helps costs optimisation by seeing where the costs are incurred and the development of further "what if" scenarios to see what can be done to achieve a decrease in costs. It actually highlights how integrated maintenance is as a whole to an organisation, the above model is only based on a single machine and the array of different aspects that have to be considered by the management is complex as it runs throughout the hierarchy in the organisation. Hence, this new idea of using simulation not only to test but as an intelligent decision making tool to help the management decide with regards to lean manufacturing.

This model is easy to understand, user friendly and interactive, which can be applied to the majority of machineries in all industries, it tells the management the cost of time, where they are spending too much money. It helps understand and question machinery i.e. "is it better to replace this machine due to too much maintenance need”. Better production scheduling due to knowing the estimated schedule delay times, this further can be translated into target improvement areas for the organisations. Further as mentioned previously on other reports, the automated response system that is fully integrated to machines and management to enable effective communication.

This model can be used as an intelligent management decision making tool as it takes into accounts all the required variables and integrated systems and philosophies.

Acknowledgment: I would like to thank all the people in the Alahaliya cement company in Libya and also the people who gave us the useful information.

\section{References}

Cassady, C.R., Murdock, W.P. Jar, \& Pohl, E.A. (2001). Selective maintenance for support Equipment involving multiple actions. European Journal of Operational Research, Vol. 129, pp. 252-8. http://dx.doi.org/10.1016/S0377-2217(00)00222-8

Duffuaa, S.O., \& Al Sultan, K.S. (1999). A stochastic programming model for scheduling Maintenance personnel. Applied Maintenance Modelling, Vol. 25, pp. 385-97. http://dx.doi.org/10.1016/S0307-904X(98)10009-4

Fonseca, D.J. (2000). A knowledge based system for preventive maintenance. Expert Systems, Vol. 17, No. 5, November. http://dx.doi.org/10.1111/1468-0394.00146

Okogbaa, O.G., \& Peng, X. (1998). Time series intervpreventive/predictive Maintenance management of multiunit systems. Proceedings of the IEEE International Conference on Systems. Man and Cybernetics, Vol. 5.

Percy, D.F., \& Kobbacy, K.A.H. (1997). Preventive maintenance modelling: a Bayesian Perspective. Journal of Quality in Maintenance Engineering, Vol. 2 No. 1, pp. 15-24. http://dx.doi.org/10.1108/13552519610113818 


\section{Macrothink}

Journal of Management Research

ISSN 1941-899X

2012, Vol. 4, No. 2

Sheu, S., Yeh, R., Lin, Y., \& Juang, M. (2001). A Bayesian approach to adaptive preventive Maintenance model. Reliability Engineering and System Safety, Vol. 71, pp. 33-44. http://dx.doi.org/10.1016/S0951-8320(00)00072-7

Wessels, W.R. (1998). Seeking an optimal scheduled maintenance interval: an analytical Characterisation of the impact of scheduled maintenance intervals on the systems reliability model. ASQ’s 52nd Annual Quality Congress Proceedings, Milwaukee.

Wildeman, R.E., Dekker, R., \& Smit, A.C.J.M. (1997). A dynamic policy for grouping Maintenance activities. European Journal of Operational Research, Vol. 99, pp. 530-51. http://dx.doi.org/10.1016/S0377-2217(97)00319-6

Xie, M., \& Ho, S.L. (1999). Analysis of repairable system failure data using time series models. Journal of Quality in Maintenance Engineering, Vol. 5 No. 1, p. 50. http://dx.doi.org/10.1108/13552519910257069

Witness Training. (2008). Manual, Lanner Group Ltd, http://www.lanner.com/21/Feb/. 